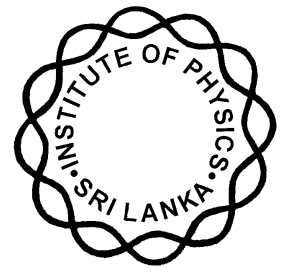

INSTITUTE OF PHYSICS - SRI LANKA

Research Article

\title{
Ionic conductivity of a PMMA based gel polymer electrolyte and its performance in solid state electrochemical cells
}

\author{
Y.M.C.D. Jayathilake ${ }^{1}$, K.S. Perera ${ }^{* 1}$, K.P. Vidanapathirana ${ }^{1}$ and L.R.A.K. \\ Bandara $^{2}$ \\ ${ }^{1}$ Department of Electronics, Wayamba University of Sri Lanka, Kuliyapitiya, Sri Lanka \\ ${ }^{2}$ Department of Physics, University of Peradeniya, Peradeniya, Sri Lanka
}

\begin{abstract}
Gel polymer electrolytes are known to be very suitable for many electrochemical devices. They have been extensively studied for lithium based electrochemical cells. But, due to several drawbacks of lithium based cells such as safety issues, handling problems and toxicity, it is the time to develop non Li based cells. In this study, ionic conductivity of a gel polymer electrolyte (GPE) based on polymethylmethacrylate, ethylene carbonate, propylene carbonate and tetrapropylammonium iodide and its performance in an $\mathrm{Mg} / \mathrm{C}: \mathrm{I}_{2}$ cell was investigated. GPE was prepared by varying salt concentration using hot pressed method and the composition, 20 PMMA / 30 EC / 30 PC / $40 \mathrm{Pr}_{4} \mathrm{~N}^{+} \mathrm{I}$ showed the highest conductivity of $5.02 \times 10^{-3} \mathrm{Scm}^{-1}$ at $28^{\circ} \mathrm{C}$. The cell in the form $\mathrm{Mg} / \mathrm{GPE} / \mathrm{C}+\mathrm{I}_{2}$ showed an average open circuit voltage of $1.9 \mathrm{~V}$. The average short circuit current was $3.3 \mathrm{~mA}$. It was possible to observe a good stability by the self discharge characteristics of the cell.
\end{abstract}

Keywords: gel polymer electrolyte; hot pressed method; polymethylmethacrylate; tetrapropylammonium iodide; electrochemical cells

\section{INTRODUCTION}

Gel polymer electrolytes (GPE) have been found to be capable of playing a significant role in numerous electrochemical applications such as batteries, smart windows, super capacitors and photo electrochemical solar cells ${ }^{1-4}$. GPEs are basically

\footnotetext{
* Corresponding Author Email: kumudu31966@gmail.com
} 
considered to be consisting of a liquid electrolyte encapsulated within a polymer matrix. Use of such gel polymer electrolytes in devices has made the 'all solid state concept' a reality. At present, many electrochemical devices that are being used and being developed are based on lithium which is known as having some drawbacks such as safety issues, handling problems and toxicity ${ }^{5,6}$. Therefore, it would be of great interest to develop non Li based systems in order to avoid the drawbacks of Li based devices. At present, there is a particular interest on anodes like $\mathrm{Mg}, \mathrm{Zn}$ and $\mathrm{Na}$ as they have some distinct advantages over $\mathrm{Li}$ such as low cost, natural abundance and environmental friendliness. Most of these metals are readily available in nature and also not hazardous. Also, several gel polymer electrolyte systems have been investigated with different cations other than $\mathrm{Li}$ and as such, studies are being carried out on non $\mathrm{Li}$ cells ${ }^{7,8}$. A special feature of such devices is that almost all of those GPEs are incorporating anions like $\mathrm{CF}_{3} \mathrm{SO}_{3}{ }^{-}, \mathrm{ClO}_{4}{ }^{-}$which are very common. However, there are some GPEs with Iodide based salts which are found to be iodide anion conductors. Such GPEs have been extensively studied for photo electrochemical solar cells where iodide ions are present as redox species ${ }^{9,10}$. In this work, the ionic conductivity of the gel polymer electrolyte based on polymethylmethacrylate (PMMA), ethylene carbonate (EC), propylene carbonate (PC) and tetrapropylammonium iodide $\left(\operatorname{Pr}_{4} \mathrm{~N}^{+} \mathrm{I}^{-}\right)$and its performance in cells of the form, Magnesium (Mg) / PMMA: EC : $\mathrm{PC}: \mathrm{Pr}_{4} \mathrm{~N}^{+} \mathrm{I}^{-} /$graphite $(\mathrm{C})+\mathrm{I}_{2}$ have been studied. The importance of this study is that properties and applications of only PMMA / $\mathrm{EC} / \mathrm{PC} / \mathrm{Pr}_{4} \mathrm{~N}^{+} \mathrm{I}^{-}$have not been reported before.

\section{EXPERIMENTAL}

\subsection{Preparation of GPE}

For the purpose of reaching at an appropriate composition, several GPE films were prepared by varying amount of $\operatorname{Pr}_{4} \mathrm{~N}^{+}$I with a constant quantity of PMMA + EC + PC. PMMA (Aldrich), EC (Aldrich), PC (Aldrich) and $\mathrm{Pr}_{4} \mathrm{~N}^{+} \mathrm{I}$ (ABCR) were used as received. The composition that yields a good ionic conductivity at normal temperatures and good mechanical stability was selected for further studies. Suitable amounts of PMMA, EC, PC and $\operatorname{Pr}_{4} \mathrm{~N}^{+} \mathrm{I}$ were mixed and the mixture was magnetically stirred further. It was heated at $80^{\circ} \mathrm{C}$ for $1 \mathrm{hr}$. Finally, the homogenous, hot mixture was pressed in between two well cleaned glass plates. Samples were prepared by varying the $\operatorname{Pr}_{4} \mathrm{~N}^{+} \mathrm{I}$ concentration (by weight).

\subsection{Characterization of GPE}

A circular disc of $14 \mathrm{~mm}$ diameter was cut from a prepared GPE film and was sandwiched in between two stainless steel electrodes (SS) inside a spring loaded sample holder. A micrometer screw gauge was used to measure the thickness of the electrolyte film. Impedance measurements for different samples were taken in the frequency range, $0.01 \mathrm{~Hz}-0.1 \mathrm{MHz}$ from room temperature to $55^{\circ} \mathrm{C}$ using Metroohm M101 impedance analyser. After determining the composition that results highest room temperature 
conductivity, it was used for further analysis.

\subsection{DC polarization test}

Disc shaped GPE sample was loaded in between two stainless steel electrodes in a sample holder and polarization measurements were done under an applied potential of $1 \mathrm{~V}$. Current drop with time was observed for several hours.

\subsection{Cell fabrication and characterization}

For the cell fabrication, a cleaned Mg strip was used as one electrode. Graphite and $I_{2}$ (Breckland Scientific Supplies) were mixed well in the ratio $4: 1$ (by weight) and pellets were prepared. Several cells in the form, Mg / GPE / C : $\mathrm{I}_{2}$ were assembled inside spring loaded brass sample holders. Open circuit voltages and short circuit currents were measured using a digital multimeter. Discharge characteristics were observed under constant loads of $1 \mathrm{M} \Omega$ and $10 \mathrm{M} \Omega$. Also, self discharge characteristics of some cells were monitored for several hours.

\section{RESULTS AND DISCUSSION}

\subsection{Ionic conductivity of GPE}

Impedance data at different $\operatorname{Pr}_{4} \mathrm{~N}^{+} \mathrm{I}$ concentrations was analysed using the Non Linear Least Square (NLLS) method developed by Boukamp (1989) and conductivity values were calculated $^{11}$. Figure 1 shows the variation of room temperature conductivity with $\mathrm{Pr}_{4} \mathrm{~N}^{+} \mathrm{I}$ concentration. At low salt concentrations, ionic conductivity was lower but with increasing concentration, ionic conductivity increased. After a certain salt concentration, further addition of salt reduced conductivity. Several other researchers have observed similar feature and have reported that the initial conductivity increase may be due to the building up of charge carriers with increasing salt content ${ }^{12,13}$.

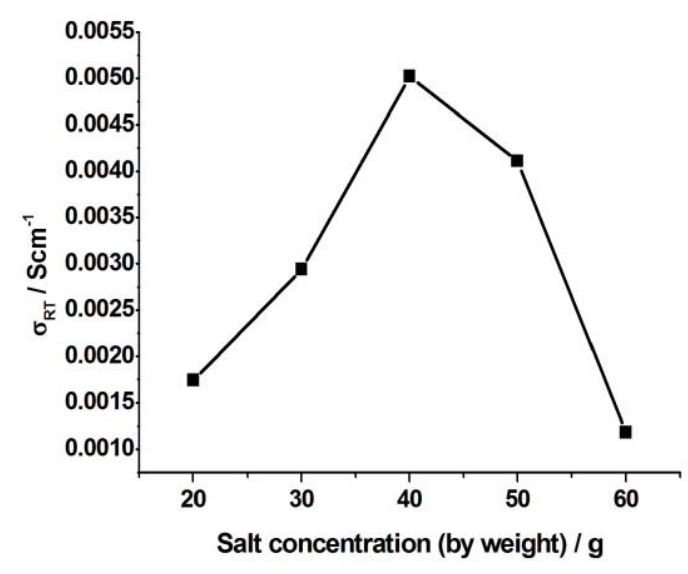

Figure 1: Room temperature conductivity variation with $\operatorname{Pr}_{4} \mathrm{NI}$ concentration (by weight) 
At high salt concentrations, build up of charge carriers is offset by the formation of neutral ion pairs as well as ion clouds made up of ion aggregates. The sample that had the optimized mechanical stability and highest ionic conductivity was of the composition, 20 PMMA / $30 \mathrm{EC} \mathrm{/} 30 \mathrm{PC} \mathrm{/} 40 \mathrm{Pr}_{4} \mathrm{~N}^{+} \mathrm{I}$ (in weight basis) and the conductivity was $5.02 \times 10^{-3} \mathrm{Scm}^{-1}$ at $28^{\circ} \mathrm{C}$. This value is rather higher than the values reported by Jeong et al., (2006) for a polyvinyl alcohol based MgTF system ${ }^{12}$. A comparable value has been observed by Lang et al., (2006) for a Sodium Iodide system with Polyacrylonitrile ${ }^{14}$. The electrolyte film made in our study had a satisfactory mechanical strength making it suitable for applications. Dependence of ionic conductivity on temperature of the sample which has the highest conductivity is illustrated in Figure 2. The curvature of the plot in Figure 2 is clearly implying that the conductivity can be described by the familiar Vogel - Tamman - Fulcher equation,

$$
\sigma=A T^{-1 / 2} \exp \left(-E_{a} /\left(T-T_{0}\right)\right.
$$

where $E_{a}$ is the pseudo activation energy, $T_{0}$ is related to glass transition temperature, $A$ is a pre exponential factor.

It can be seen from the plot that when the temperature increases, the conductivity also increases as expected. This is evidently due to decrease of viscosity with increasing temperature ${ }^{13}$.

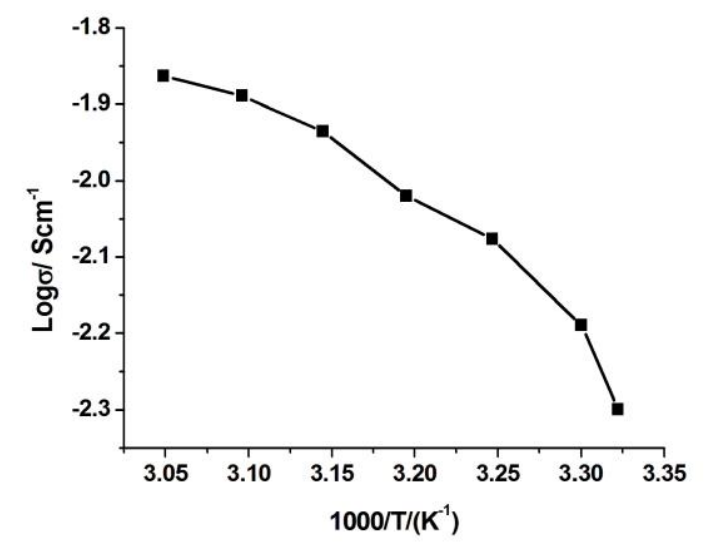

Figure 2: Temperature dependence of the conductivity of the sample which showed the highest conductivity at $28^{\circ} \mathrm{C}$

\subsection{DC polarization test}

DC polarization curve taken with blocking electrodes is shown in Figure 3. The value of ionic transference number has been calculated and found to be 0.9 . This value clearly shows that overall conductivity of GPE is predominantly ionic ${ }^{15,16}$. 


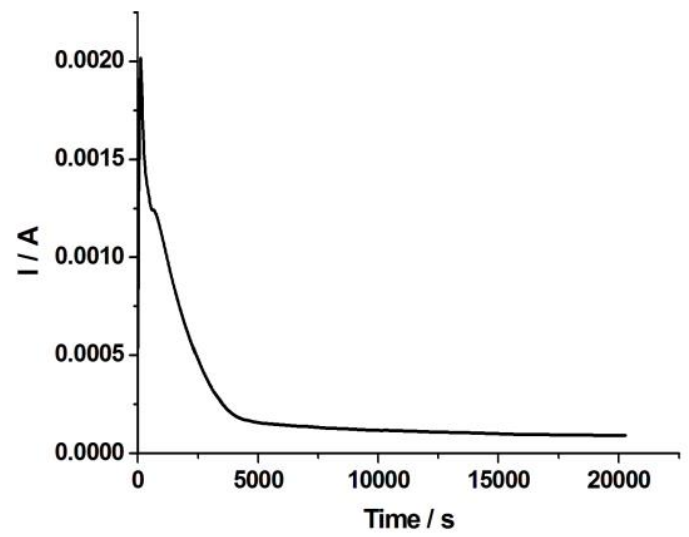

Figure 3: DC polarization curve taken with blocking electrodes at $28^{\circ} \mathrm{C}$

\subsection{Performance of cells}

The cell voltage discharge profiles recorded as a function of time for two loads, $1 \mathrm{M} \Omega$ and $10 \mathrm{M} \Omega$ are shown in Figure 4. The possible electrochemical reactions can be stated as follows.

At the anode: $\quad M g \leftrightarrow M g^{2+}+2 e$

At the cathode: $\quad I_{2}+2 e \leftrightarrow 2 I^{-}$

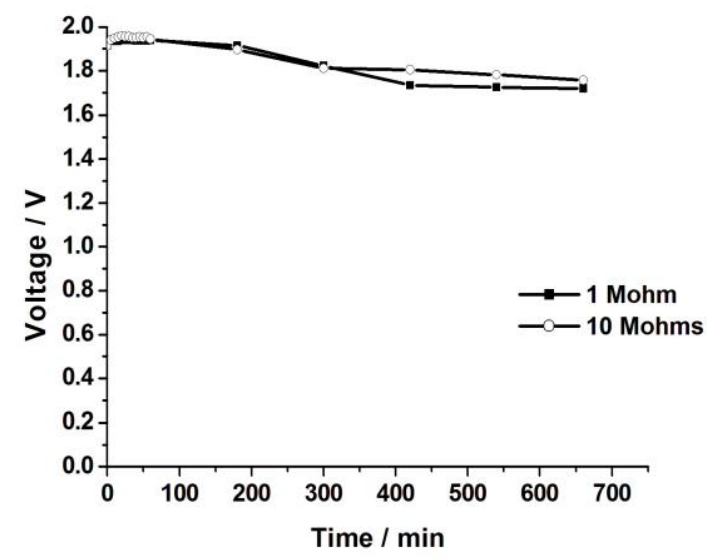

Figure 4: Discharge curves for the cells, $\mathrm{Mg} / \mathrm{GPE} / \mathrm{C}: \mathrm{I}_{2}$ under constant loads of $1 \mathrm{M} \Omega$ and $10 \mathrm{M} \Omega$ at $28^{\circ} \mathrm{C}$ 
Open circuit voltage has an average value of $1.9 \mathrm{~V}$ which is an appealing sufficient value for low power requirements. The average short circuit current was $3.3 \mathrm{~mA}$. Under both loads, cells show more or less similar discharge characteristics. For a voltage reduction of $0.2 \mathrm{~V}$, it has taken more than 10 hours. Average currents during discharge for $1 \mathrm{M} \Omega$ and $10 \mathrm{M} \Omega$ are $2 \mu \mathrm{A}$ and $0.2 \mu \mathrm{A}$ respectively. These two values are little lower but, make the cells suitable for low power applications.

\section{CONCLUSIONS}

The GPE system considered in this project is a good ionic conductor having negligible electronic conductivity. Therefore, it is quite suitable not only for electrochemical solar cells but also for primary cells. The cells having the electrodes other than $\mathrm{Li}$ are suitable for low power requirements such as illumination of LEDs. Those cells are having no environmental pollution issues as well as leaking, sealing problems. The results of this study may generate interest on cells based on GPEs with different types of anions instead of the commonly used ones.

\section{ACKNOWLEDGMENT}

Financial assistance provided by National Research Council of Sri Lanka (NRC - 12-109) is highly appreciated.

\section{References}

1. H. Yang, M. Huang, J. Wu, Z. Lan, S. Hao and J. Lin, The polymer gel electrolyte based on poly(methyl methacrylate) and its application in quasi solid state dye sensitized solar cells, Materials Chemistry and Physics, 110 , (2008) 38-42

2. A. Gupta and S.K. Tripathi, Effect of anionic size of PMMA based polymer grel electrolyte for redox capacitor, International Journal of Engineering Research and Applications, 3(1), (2013) 1908-1911

3. S.N. Asmar, M.Z. Kufian, S.R. Majid and A.K. Arof, Preparation and characterization of magnesium ion gel polymer electrolytes for application in electrical double layer capacitors, Electrochim Acta, 57, (2011) 91-97

4. M. Yang and J. Hou, Membranes in Li ion batteries, Membranes, 2, (2012) 367-383

5. I. Yamada, Yasutoshi Iriyama, Takeshi Abe and Zempachi Ogumi, Lithium-ion transfer between LixCoO2 and polymer gel electrolytes, Science and Technology of Advanced Mater, $\underline{7}$, (2006) 519-523

6. R.L. Lavall, S. Ferrari, C. Tomasi, M. Marzantowicz, E. Quartarone, M. Fagnoni, P. Mustarelli and M.L. Saladino, MCM-41 silica effect on gel polymer electrolytes based on thermoplastic polyurethane, Electrochim Acta, 60, (2012) 359-365 
7. D. Kumar and S.A. Hashmi, Ionic liquid based sodium ion conducting gel polymer electrolytes, Solid State Ionics, 181, (2010) 416-423

8. J.P. Sharma and S.S. Sekhon, PMMA based polymer gel electrolyte containing NH4PF6: Role of molecular weight of polymer, Materials Science and Engineering, B129, (2006) 104-108

9. M.A.K.L. Dissanayake, C. A. Thotawaththage, G.K. R. Senadheera, T.M.W.J. Bandara, W.J.M.J.S.R. Jayasundara and B.F. Mellander, Efficiency enhancement in dye sensitized solar cells based on PAN gel polymer electrolyte with Pr4NI + MgI2 binary iodide salt mixture, J. Appl. Electrochem, $\underline{43}$, (2013) 891-901

10. T.M. W.J. Bandara, T. Svensson, M.A.K.L. Dissanayake, M. Furlani, W.J.M.J.S.R. Jayasundara, P.S.L. Fernando, I. Albinsson and B.F. Mellander, Conductivity behavior in novel quasi-solid state electrolyte based on polyacrylonitrile and tetrahexylammonium iodide intended for dye sensitized solar cells, J. Natn. Sci. Foundation Sri Lanka, 41(3), (2013) 175-184

11. B.A. Boukamp, Equivalent Circuit Users Manual, (1989)

12. S.K. Jeong, Y.K. Jo and N.J. Jo, Decoupled ion conduction mechanism of poly (vinyl alcohol) based Mg conducting solid polymer electrolyte, Electrochim Acta, 52, (2006) 1549-1555

13. D. Ravindran and P. Vickraman, $M g 2+$ Ionic conductivity behavior of mixed salt system in PVA-PEG blend matrix, International J of Scientific and Research Publications, 2(12), (2012) $1-4$

14. L. Lang, Jihuai Wu, Dongbo Wang, Sancun Hao, Jianming Lin and Yunfang Huang, Quasi solid state dye sensitized solar cells based on gel polymer electrolyte with poly(acrylonitrile - co - styrene)/NaI $+I_{2}$, Solar Energy, 80(11), (2006) 1483-1488

15. N.H. Zainol, S.M. Samin, L. Othman, K.B. Mid Isa, W.G. Chong and Z. Osman, Magnesium ion based gel polymer electrolyte: Ionic conduction and Infrared spectroscopy studies, International J of Electrochem Science, $\underline{8}$, (2013) 3602-3614

16. A.R. Polu, R. Kumar and K.V. Kumar, Ionic conductivity and electrochemical cell studies of new Mg2+_ ion conducting PVA/PEG based polymer blend electrolytes, Adv. Mat. Lett., 3(5), (2012) 406-409 